\title{
Learning impact of education during Pulmonary Rehabilitation program. An observational short-term cohort study
}

\author{
E. Crisafulli1, S. Loschi1, C. Beneventi ${ }^{1}$, A. De Biase1, \\ B. Tazzioli ${ }^{1}$, A. Papetti 1 , C. Lorenzi ${ }^{1}$, E.M. Clini1,2
}

ABSTRACT: Learning impact of education during Pulmonary Rehabilitation program. An observational shortterm cohort study. E. Crisafulli, S. Loschi, C. Beneventi, A. De Biase, B. Tazzioli, A. Papetti, C. Lorenzi, E.M. Clini. Background. Among the several components constituting a pulmonary rehabilitation (PR) course, education may contribute to an individual's recognition of symptoms and worsening of the disease. However, the specific benefits of education is far greater than can be clearly documented to the health care providers. The aim of our preliminary study was to assess the learning impact of educational sessions (ES) in Chronic Obstructive Pulmonary Disease (COPD) patients referred to standard PR.

Methods. Six ES on 3 areas (Symptoms-Therapies, Aids, Mood) were applied during PR at our clinic. The learning effect was prospectively evaluated by a specific questionnaire (ESQ) in 285 COPD patients (age 69 \pm 8 years, $\mathrm{FEV}_{1} 53 \pm 14 \%$ pred), then grouped into those who have completed ES (Completers group, $\mathbf{n = 2 2 6}$ ) or who did not (mean $2 \pm 1 \mathrm{ES}$ ) (Control group, $\mathrm{n}=59$ ). Total and partial ESQ scores, and PR outcomes (6-minute walking test6MWD, effort-dyspnoea at Medical Research Council scale-MRC, and health-related quality of life scale-SGRQ) were assessed in a pre (T0) to post (Tend) design.

Results. Similar improvement in PR outcomes was recorded in both groups at Tend, whereas ESQ total and partial scores significantly increased in 'Completers' only $(\boldsymbol{p}<0.001)$. ESQ-Aids score improved to a greater extent in Completers than in Control $\mathbf{( + 0 . 6 0 \pm 1 . 0 3}$ vs $+\mathbf{0 . 2 7} \pm 1.27$ point respectively, $p=0.036)$. A higher proportion of $\mathrm{Com}$ pleters improved above the median change of both ESQ total and aids scores $(p<0.05)$.

Conclusion. Attending educational sessions produces a specific short-term learning effect during rehabilitation of COPD patients.

Monaldi Arch Chest Dis 2010; 73: 2, 64-71.

Keywords: Education, COPD, Rehabilitation, Self-management.

I Villa Pineta Hospital, Pulmonary Rehabilitation Unit, Pavullo n/F (MO),

2 University of Modena, DAI Oncology, Haematology and Pneumology, Modena, Italy.

Correspondence: Prof. Enrico M. Clini, University of Modena and Ospedale Villa Pineta, Dept. of Oncology, Haematology and Pneumology, Ospedale Villa Pineta, Via Gaiato 127, 41026 Pavullo (MO), Italy; e-mail: enrico.clini@unimore.it

\section{Introduction}

Pulmonary Rehabilitation (PR), a non-pharmacological comprehensive intervention for disabled chronic respiratory patients, proves effective in terms of exercise tolerance and perceived symptoms (e.g. dyspnoea and/or fatigue) in Chronic Obstructive Pulmonary Disease (COPD) individuals [1].

Among the several components integrating a formal rehabilitation setting, education and selfmanagement may substantially contribute to the individual's early recognition of symptoms and worsening of the disease $[2,3]$, through recalling information on the pathophysiological alterations and reinforcing skills.

Actual recommendations always suggest including education during PR course, nonetheless, the relative and specific effectiveness of this component throughout is still not sufficiently documented to health care providers [4].

The present preliminary study, therefore, has been undertaken to assess the learning impact of structured educational sessions (ES) applied dur- ing a standard PR program delivered to disabled COPD patients.

\section{Methods}

\section{Patients}

Patients suffering from COPD referred to our clinic for rehabilitation purposes in between January and December 2008 were studied. Diagnosis and classification were according to the Global Initiative for Chronic Obstructive Pulmonary Disease (GOLD) guidelines [5].

Only clinically stable patients entered the study. Those suffering from recent acute exacerbation of their disease (in the preceding 4 weeks) were excluded. Moreover, patients with respiratory conditions other than COPD (either obstructive or restrictive), associated malignancies, or any unstable clinical condition (e.g. severe heart failure, neuro-motorial conditions) which might have interfered with adherence, or patients with cognitive impairment that might have interfered with under- 
standing and learning, were not included. All the selected patients gave their informed consent to participate in the study.

Figure 1 shows the flow diagram of the study cohort.

\section{Study design}

The institutional review board at our hospital approved this observational study; all procedures were conducted according to the Declaration of Helsinki.

The study design was a prospective short-term pre-to-post comparison of measurements in all individuals. Comparison was made in the whole sample and between the following two groups: patients who have completed all the educational sessions (ES) (Completers group, $\mathrm{n}=226$ ), or those who did not (number of $\mathrm{ES}=2 \pm 1$ ) (Control group, $\mathrm{n}=59$ ) due to clinical or personal reasons.

\section{PR program}

The patient's selection to PR was made according to the ATS/ERS joint statement [1]. All the selected COPD patients performed a standard PR program with outcome measures taken at the beginning and immediately prior to discharge; details on this program have been reported previously from our group [6]; each daily session lasted three hour and included endurance and resistance training of the peripheral muscles, as recommended [1]. Educational course (see below), psychological and/or nutritional support (if appropriate) completed the program.

The duration of PR was over a minimum of 15 consecutive sessions.

\section{Educational course}

This was provided by 6 different ES lasting 1 hour each, which integrated the rehabilitation program. Patients were grouped to attend each lesson in the morning at the same time and following the training activities, but they were left free to choosing if they wanted to participate in each lesson.

Lessons were held for pertinence by different "health educators" (physician, respiratory therapist, nurse and psychologist) on the following topics: anatomy and physiology of pulmonary system,

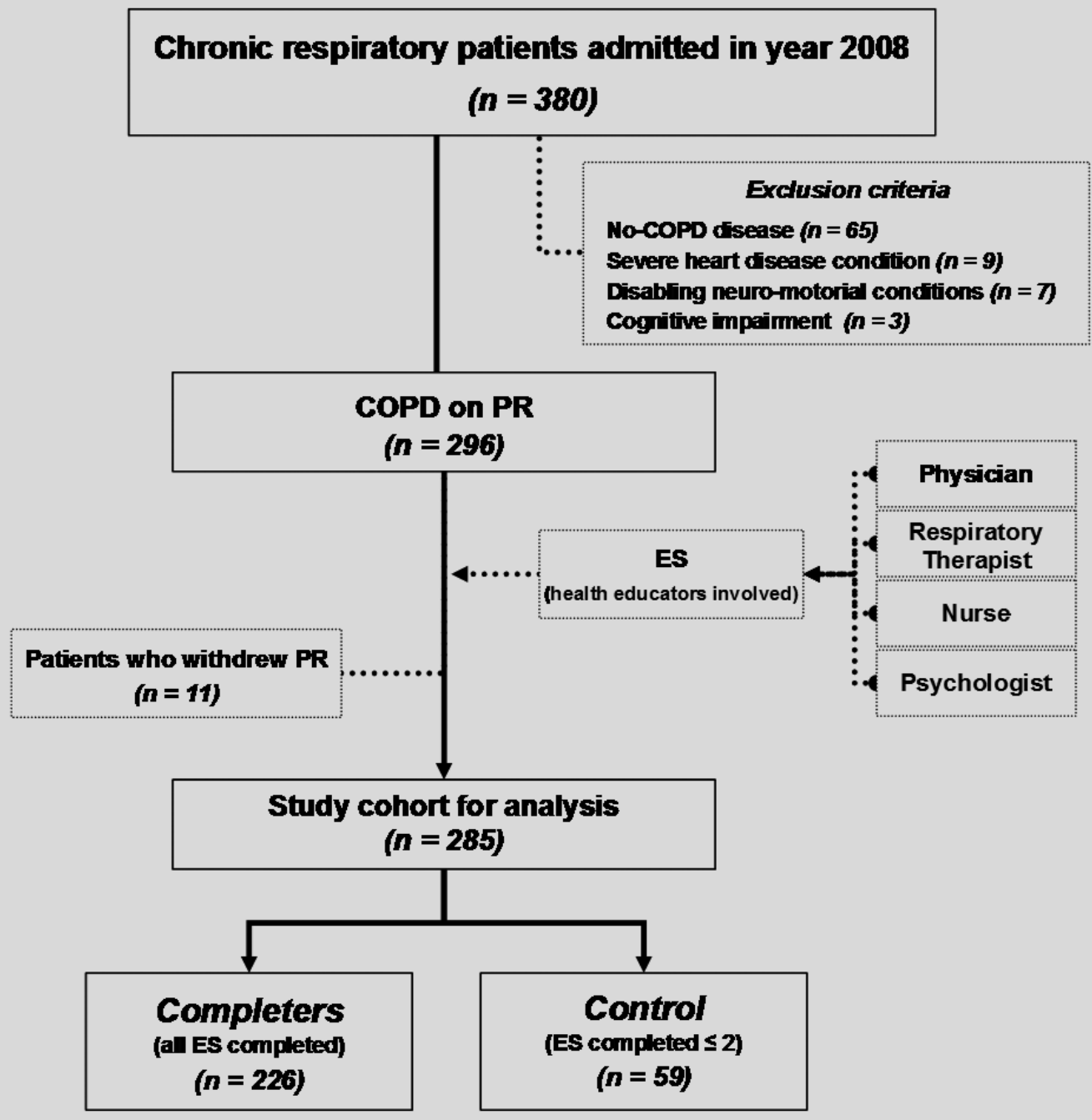

Fig. 1. - Study flow diagram. PR: Pulmonary Rehabilitation; ES: Educational Sessions. 
early recognition of symptoms and signs of exacerbation (physician), role of muscle training and chest physiotherapy in pulmonary diseases (respiratory therapist), domiciliary use and management of respiratory aids, oxygen or drug inhalers (nurse and respiratory therapist), management of mood disturbances (psychologist).

Access to each ES was registered and attendants signed their presence.

Any other specific information and/or educational material (i.e. brochure) on specific non included topics were also encouraged and proposed to each patient according to his/her individual needs; however, these topics were covered over and above the standard delivery of ES.

\section{Measures}

\section{GENERAL DATA}

Anthropometric and demographic characteristics of all the selected patients were collected at study entry. Lung function in terms of dynamic volumes (forced expiratory capacity in the 1st second-FEV 1 , and $\mathrm{FEV}_{1}$ to forced vital capacity-FVC ratio) was recorded by means of a spirometer (Masterscope; Jaeger; Hoechberg, Germany); parameters were expressed both as absolute or percentage of predicted values according to the equation of Quanjer [7].

\section{OUTCOME MEASURES}

These measurements were taken within 24-48 hours from the beginning of PR (T0) and immediately prior to discharge (Tend) after the program has been completed.

\section{LEARNING QUESTIONNAIRE}

A specific questionnaire (ESQ) completed by all patients in the study (without the assistance of any operator) represented the clinical tool we used to assess the level of patient's knowledge and the learning impact of the ES course. This multiplechoice questionnaire (see Appendix) was composed of ten questions (one correct answer for each question) grouped in three different areas: Symptoms-therapy, Aids, Mood. Questions were previously elaborated and selected by our multidisciplinary group and judged on "what is relevant for the patient to know" in each topic. A formal group brainstorming and evaluation of website accessible materials for COPD patients [8] preceded the questionnaire composition.

For each correct answer 1 point was assigned, the total score therefore ranged from 0 (minimum) to 10 (maximum).

\section{SPECIFIC PR MEASURES}

Exercise tolerance, as measured by 6-minute walked distance (6MWD) [9], perceived effortdyspnoea, as recalled by means of a five-point $(0$ as best, 4 as worst) modified Medical Research Council (MRC) scale [10], and specific health-related quality of life questionnaire (St. George's Respiratory Questionnaire-SGRQ) validated in Italian language [11], were recorded as general PR outcomes.

\section{Statistical analysis}

Statistical analysis was carried out using SPSS software (SPSS 8.0 for Windows; SPSS, Chicago, IL).

All values are expressed as mean (with SD) or frequency ( $\mathrm{nr}$ or \%) and presented in the whole cohort or in the two groups. Statistical comparison between groups and times for different size parameters was made using test $t$ of Student and by a General Linear Model. The Wilcoxon and KruskalWallis tests were applied for comparison of nonparametric variables. A chi-square test was added for comparison between number (and \%) of patients in each group who improved above the median change of the questionnaire scores (total and partial).

In any case a result with a statistical probability $(p)<.05$ was considered to be of significant difference.

\section{Results}

296 COPD patients were selected for this study and of them 285 (66\% male) completed the rehabilitation course and had their results analysed (see figure 1). Withdrawal rate from PR was therefore about $4 \%$.

Most of these patients $(79 \%, n=226)$ completed ES course and were thus grouped into Completers, whereas 59 remained as Control.

$68 \%$ of controls did not complete ES due to voluntary withdrawal (they did not attend the scheduled lessons), while the remaining $32 \%$ had clinical problems (intercurrent symptoms such as worsening dyspnea, malaise, back or joint pain) which temporarily precluded their chance to reach the educational room.

The baseline descriptive characteristics of patients are shown in table $1.67 \%$ of them were in stage III and IV according to GOLD classification, whereas 30\% were on long-term oxygen (LTOT) at home. No differences were recorded between groups.

Table 2 shows total and partial ESQ scores, as recorded at study entry, which were similar in the two groups. Analysis of pre-to-post group comparison of both specific PR outcomes and ESQ scores is shown in table 3. Exercise tolerance and perceived effort-dyspnoea significantly $(p=0.001)$ and similarly improved in both groups, whereas ESQ total and partial scores significantly changed $(p=0.001)$ in Completers. The analysis of difference of both ESQ absolute value (table 4) and the proportion of patients who improved above the median change of the questionnaire scores (table 5) as obtained after PR further confirmed a significant change in favour of Completers.

\section{Discussion}

It is likely that educational component of a structured comprehensive rehabilitation program may attract individuals to a more active participation and collaboration (compliance) in the rehabilitative track. Indeed, compliance is almost known 
Table 1. - Anthropometric and clinical characteristics in the study cohort. Data presented as mean (SD) of percentage value

\begin{tabular}{|c|c|c|c|c|c|}
\hline & & Study Cohort & Completers Group & Control Group & \\
\hline & & $(n=285)$ & $(n=226)$ & $(n=59)$ & $P$ \\
\hline$M: F$ & $n r$ & $188 / 97$ & $151 / 75$ & $37 / 22$ & 0.502 \\
\hline Age & years & $69.9 \pm 8.0$ & $70.2 \pm 8.2$ & $68.2 \pm 6.7$ & 0.128 \\
\hline BMI & $\mathrm{kg} \cdot \mathrm{m}^{-1}$ & $26.0 \pm 4.8$ & $25.7 \pm 4$ & $226.1 \pm 4.0$ & 0.451 \\
\hline \multirow[t]{2}{*}{$\mathrm{FEV}_{1}$} & $l$. & $1.05 \pm 0.58$ & $1.01 \pm 0.49$ & $1.08 \pm 0.63$ & 0.309 \\
\hline & $\%$ pred. & $53.4 \pm 14.4$ & $50.1 \pm 12.9$ & $54.5 \pm 10.0$ & 0.186 \\
\hline $\mathrm{FEV}_{1} / \mathrm{FVC}$ & $\%$ & $53.7 \pm 12.8$ & $54.1 \pm 10.1$ & $52.3 \pm 11.5$ & 0.865 \\
\hline GOLD staging & & & & & 0.128 \\
\hline Mild & $n r(\%)$ & $4(1.4)$ & $3(1.3)$ & $1(1.6)$ & \\
\hline Moderate & $n r(\%)$ & $91(31.8)$ & $63(27.8)$ & $28(47.4)$ & \\
\hline Severe & $n r(\%)$ & 85 (29.9) & $71(31.4)$ & $14(23.7)$ & \\
\hline Very severe & $n r(\%)$ & $105(36.8)$ & $89(39.3)$ & $16(27.1)$ & \\
\hline
\end{tabular}

M: male; F: female; BMI: Body Mass Index; $\mathrm{FEV}_{1}$ : Forced expiratory volume in 1 st sec; $\mathrm{FEV}_{1} / \mathrm{FVC}$ : Tiffenau index or ratio $\mathrm{FEV}_{1} / \mathrm{FVC}$, Forced vital capacity; GOLD: Global Initiative for Chronic Obstructive Pulmonary Disease.

to represent a "key point" of success in PR [12]. In the present study, about $80 \%$ of patients attended and completed the ES. This is new and interesting data which has emerged from real life. A recent study in PR found approximately a $90 \%$ attendance rate among outpatients COPD [13], but gave no information on attendance rate at any single PR component including education course.

Over recent years, the role of education is considered to be of increasing interest for COPD patients' management. A current method of teaching by means of frontal lessons is a useful means of instructing patients regarding their disease and its consequences, and to challenge them through change in lifestyle to accomplish the best possible control of their clinical condition once at home $[14,5]$.
Although literature still shows no firm and consistent benefits from formal education [16-18] two recent studies centred on patient's "self-management" with the aim of recognising exacerbation as early as possible, resulted in substantial reduction of hospitalisation rate over 1-year [3] and up to 2-year [4] of follow-up.

Our study documented that educational sessions produce a specific short-term learning effect during a standard rehabilitation program in COPD patients, in particular regarding the management of respiratory aids (e.g. oxygen or devices for inhaled therapy) in daily use. In a narrow analogy with previous studies [19] and international guidelines [1, 2], effectiveness of PR program in terms of general function is here provided by results of both exercise tolerance, breathlessness and healtd-

Table 2. - ESQ scores in the study cohort as assessed at admission. Data presented as mean (SD)

\begin{tabular}{|c|c|c|c|c|c|}
\hline & & Study Cohort & Completers Group & Control Group & \\
\hline & & $(n=285)$ & $(n=226)$ & $(n=59)$ & $P$ \\
\hline \multicolumn{6}{|l|}{ Questionnaire scores } \\
\hline SYMPTOMS-THERAPY & score & $2.75 \pm 1.06$ & $2.74 \pm 1.02$ & $2.79 \pm 1.22$ & 0.734 \\
\hline AIDS & score & $2.60 \pm 0.95$ & $2.60 \pm 0.92$ & $2.62 \pm 1.06$ & 0.856 \\
\hline MOOD & score & $1.24 \pm 0.70$ & $1.24 \pm 0.69$ & $1.25 \pm 0.73$ & 0.950 \\
\hline TOTAL & score & $6.63 \pm 1.85$ & $6.59 \pm 1.79$ & $.67 \pm 2.08$ & 0.417 \\
\hline
\end{tabular}


Table 3. - Time course of specific PR outcomes (Part $A)$ and ESQ scores (Part $B)$ as assessed throughout PR. Data presented as mean (SD)

\begin{tabular}{|c|c|c|c|c|c|c|c|c|}
\hline \multirow[t]{2}{*}{ PART A } & & \multicolumn{3}{|c|}{$\begin{array}{l}\text { Completers Group } \\
\qquad(n=226)\end{array}$} & \multicolumn{3}{|c|}{$\begin{array}{l}\text { Control Group } \\
\qquad(n=59)\end{array}$} & \multirow{2}{*}{$p^{*}$} \\
\hline & & T0 & T end & $p$ & T0 & $T$ end & $p$ & \\
\hline 6MWD & meters & $354.6 \pm 101.7$ & $422.7 \pm 107.1$ & 0.001 & $354.2 \pm 88.0$ & $429.3 \pm 85.5$ & 0.001 & 0.844 \\
\hline MRC & score & $3.25 \pm 0.93$ & $2.22 \pm 0.90$ & 0.001 & $3.46 \pm 0.89$ & $2.42 \pm 0.86$ & 0.001 & 0.178 \\
\hline SGRQ & score & $36.33 \pm 14.65$ & $25.52 \pm 12.91$ & 0.001 & $34.45 \pm 15.18$ & $24.38 \pm 10.69$ & 0.001 & 0.423 \\
\hline \multirow[t]{2}{*}{ PART B } & & \multicolumn{3}{|c|}{$\begin{array}{c}\text { Completers Group } \\
\qquad(n=226)\end{array}$} & \multicolumn{3}{|c|}{$\begin{array}{c}\text { Control Group } \\
(n=59)\end{array}$} & \\
\hline & & T0 & T end & $p$ & T0 & T end & $p$ & \\
\hline \multicolumn{9}{|l|}{ Questionnaire scores } \\
\hline SYMPTOMS-THERAPY & score & $2.74 \pm 1.02$ & $3.21 \pm 0.91$ & 0.001 & $2.79 \pm 1.22$ & $3.00 \pm 1.14$ & 0.171 & 0.825 \\
\hline AIDS & score & $2.60 \pm 0.92$ & $3.20 \pm 0.84$ & 0.001 & $2.62 \pm 1.06$ & $2.89 \pm 1.09$ & 0.107 & 0.956 \\
\hline MOOD & score & $1.24 \pm 0.69$ & $1.49 \pm 0.63$ & 0.001 & $1.25 \pm 0.73$ & $1.42 \pm 0.67$ & 0.086 & 0.709 \\
\hline TOTAL & score & $6.59 \pm 1.79$ & $7.91 \pm 1.80$ & 0.001 & $6.67 \pm 2.08$ & $7.20 \pm 2.21$ & 0.077 & 0.747 \\
\hline
\end{tabular}

6MWD: 6-min walked distance test; MRC: Medical Research Council breathlessness score; SGRQ: St. George's Respiratory Questionnaire total score. * Comparison between groups (Completers vs Control groups).

related quality of life (table 3, part A), which did not parallel the observed gain associated with learning (table 3, part B).

Both total and partial ESQ mean scores significantly improved at the end of the rehabilitation period only in patients who fully attended the educational course, while they remained unchanged in those patients who did not. In addition, both analysis of difference of ESQ absolute value (table 4) and the proportion of patients who improved above the median change of the questionnaire scores (table 5) confirmed the adjunctive gain on learning in Completers only.

It is likely that direct message of our educational lessons supported this result, thus enabling patients who complied with all the lessons to achieve this extra gain irrespective on their severity and/or functional complexity (i.e. presence or absence of respiratory failure).

Despite the lack of unequivocal scientific evidence on the real learning benefit from a single therapeutic modality in patients with COPD [20, $21]$, education component has the aim not only of encouraging the active participation and collaboration of the rehabilitation program but also (and especially) to "teach" some technical and behavioural aspects of daily living.

The aim of this type of learning would be to focus the patient's attention on the chronic aspects of his/her disease, such as the early signs of exacer-

Table 4. - Analysis of difference in ESQ scores between groups as obtained at discharge (Tend). Data presented as mean (SD)

\begin{tabular}{cccccc}
\hline & & Study Cohort & Completers Group & Control Group & $\boldsymbol{p}$ \\
\cline { 3 - 5 } & & $(\boldsymbol{n = 2 8 5})$ & $(\boldsymbol{n = 2 2 6})$ & $(\boldsymbol{n = 5 9})$ & \\
\hline Questionnaire scores $(\Delta)$ & & & & & 0.077 \\
\hline SYMPTOMS-THERAPY & score & $+0.41 \pm 1.02$ & $+0.46 \pm 0.99$ & $+0.20 \pm 1.12$ & $\mathbf{0 . 0 3 6}$ \\
\hline AIDS & score & $+0.53 \pm 1.09$ & $+0.60 \pm 1.03$ & $+0.27 \pm 1.27$ & 0.502 \\
\hline MOOD & score & $+0.22 \pm 0.75$ & $+0.24 \pm 0.75$ & $+0.16 \pm 0.74$ & 0.094 \\
\hline TOTAL & score & $+1.22 \pm 1.85$ & $+1.31 \pm 1.79$ & $+0.86 \pm 2.03$ & \\
\hline
\end{tabular}

$\Delta$ : Difference of variables obtained between the end and begin of PR program. 
Table 5. - Comparison between proportion of patients in each group who improved above the median change of the questionnaire scores (total and partial). Data presented as $\mathrm{n}(\%)$

\begin{tabular}{ccccc}
\hline & & Completers Group & Control Group & \multirow{2}{*}{$\boldsymbol{x}^{2}$} \\
\cline { 3 - 5 } & & $(\boldsymbol{n = 2 2 6})$ & $(\boldsymbol{n = 5 9 )}$ & 0.413 \\
\hline SYMPTOMS-THERAPY & $n(\%)$ & $197(87.1)$ & $49(83.0)$ & $\mathbf{0 . 0 2 0}$ \\
\hline AIDS & $n(\%)$ & $202(89.3)$ & $46(77.9)$ & 0.639 \\
\hline MOOD & $n(\%)$ & $198(87.6)$ & $53(89.8)$ & $\mathbf{0 . 0 3 9}$ \\
\hline
\end{tabular}

bation, to prevent unfavourable consequences [22] and to increase general adherence to therapies $[8,23]$, in other words to improve the "self-efficacy" [3]. Indeed, it's commonly recognised that COPD exacerbation may cause several clinical adverse events both at lung [24] or systemic level [25], thus increasing health-care costs [26] and mortality [27]. The correct delivery of drugs and the use of respiratory aids represent aspects of main importance in the long term. When compared to those patients who failed to fully attend the ES in our study, the proportion of COPD patients who completed the educational course reported a significantly higher change of ESQ-Aids score above the median observed absolute change (table 5), which is likely to enable them to improve these skills even after returning home.

Given that compliance is a key element in the management of chronic diseases and patient's adherence to therapies [28] a formal program of education has not only the aim of "teaching" concepts and "training" techniques, but also to "educate" the patients; so that, he/she becomes more aware of any consequence derived from a irresponsible use or a no-use of requested devices and aids. This might further translate in a true economic advantage in the long-term; indeed, cost saving from change in lifestyle has been already demonstrated in COPD [29].

Notwithstanding, our study presents several limitations. First, the absence of a control group, we have only assessed the learning effect of a specific intervention in a short period after rehabilitation nor we did assess the patients' change in lifestyle after program discharge over a formal longer follow-up. Therefore, we can only speculate any further advantage in the patient's daily living once he/she returned home.

Second, one should note the very different amount of patients in the two study groups. The number of control patients was determined ex post since we did not expect precisely the rate of adherence to our ES course (which can vary consistently in different population and/or setting).

Future studies with a randomised trial design should address the short and (hopefully) long-lasting effect derived from a structured educational program in COPD patients, and even assess the possible cost-benefit advantage of such intervention.
In conclusion, our preliminary research has fairly shown that attending formal education is likely to produce a specific learning effect during standard rehabilitation delivered to COPD patients. As a consequence, we might speculate that formal education enhances patients' self-management and practical skills in their daily lives.

\section{References}

1. American Thoracic Society/European Respiratory Society. Statement on Pulmonary Rehabilitation. Am J Respir Crit Care Med 2006; 173: 1390-1413.

2. Bourbeau J, Julien M, Maltais F, et al. Chronic Obstructive Pulmonary Disease axis of the Respiratory Network Fonds de la Recherche en Santé du Québec. Reduction of hospital utilization in patients with chronic obstructive pulmonary disease: a disease-specific self-management intervention. Arch Intern Med 2003; 163: 585-591.

3. Gadoury M-A, Schwartzman K, Rouleau M, et al for the Chronic Obstructive Pulmonary Disease axis of the Respiratory Health Network, Fonds de la recherche en santé du Québec (FRSQ). Self-management reduces both short- and long-term hospitalisation in COPD. Eur Respir J 2005; 26: 853-857.

4. Effing T, Monninkhof EM, van der Valk PD, et al. Selfmanagement education for patients with chronic obstructive pulmonary disease. Cochrane Database Syst Rev 2007; 4: CD002990.

5. Global Initiative for Chronic Obstructive Pulmonary Disease (GOLD). Global Strategy for the diagnosis, management and prevention of Chronic Obstructive Pulmonary Disease: NHLBI/WHO workshop report, NIH Publication 2701. 2003; http: //www.goldcopd.com/

6. Rossi G, Florini F, Romagnoli M, et al. Length and effectiveness of pulmonary rehabilitation in outpatients with chronic airway obstruction. Chest 2005; 127: 105-109.

7. Quanjer PH, Tammeling GJ, Cotes JE. Lung volumes and forced ventilatory flows: report Working Party Standardization of Lung Function Tests, European Community for Steel and Coal; official statement of the European Respiratory Society. Eur Respir J Suppl 1993; 16: 5-40.

8. Maltais F, Bourbeau J, Shapiro S, et al for the Chronic Obstructive Pulmonary Disease Axis of the Respiratory Health Network, Fonds de la recherche en santé du Québec. Effects of Home-Based Pulmonary Rehabilitation in Patients with Chronic Obstructive Pulmonary Disease. Ann Intern Med 2008; 149: 869-878.

9. American Thoracic Society Statement. Guidelines for the six-minute walk test. Am J Resp Crit Care Med 2002; 166: 111-117 
10. Fletcher CM. Standardised questionnaire on respiratory symptoms: a statement prepared and approved by the MRC Committee on the aetiology of Chronic Bronchitis (MRC breathlessness score). Br Med J 1960; 2: 1665.

11. Carone M, Bertolotti G, Anchisi F, Zotti AM. The St. George's Respiratory Questionnaire (SGRQ): Italian version. Rassegna Patol App Respir 1999; 14: 31-37.

12. Ambrosino N, Foglio K. Selection criteria for pulmonary rehabilitation. Respir Med 1996; 90: 317-22.

13. Sabit R, Griffiths TL, Watkins AJ, et al. Predictors of poor attendance at an outpatient pulmonary rehabilitation programme. Respir Med 2008; 102: 819-824.

14. Bodenheimer T, Lorig K, Holman H, Grumbach K. Patient self-management of chronic disease in primary care. JAMA 2002; 288: 2469-2475

15. Lareau SC, Insel KC. Patient and family education. In: Hodgkin JR, Celli BR, Connors GL. Pulmonary rehabilitation, 3rd ed. St. Louis: Elsevier 2000.

16. Watson PB, Town GI, Holbrook N, Dwan C, Toop LJ, Drennan CJ. Evaluation of a self-management plan for chronic obstructive pulmonary disease Eur Respir $J$ 1997; 10: 1267-1271

17. Monninkhof E, van der Valk P, van der Palen J, van Herwaarden C, Zielhuis G. Effects of a comprehensive self-management programme in patients with chronic obstructive pulmonary disease. Eur Respir J 2003; 22: 815-20.

18. Monninkhof E, Van der Valk P, Van der Palen J, Van Herwaarden C, Partridge MR, Zielhuis G. Self-management education for patients with chronic obstructive pulmonary disease: a systematic review. Thorax 2003; 58: 394-8.

19. Lacasse Y, Brousseau L, Milne S, et al. Pulmonary Rehabilitation For Chronic Obstructive Pulmonary Disease (Cochrane Review). The Cochrane Library, Issue 2, 2004. Chichester, Uk: John Wiley \& Sons, Ltd., 2004. Cochrane Database Syst Rev 2002; 3: Cd003793.
20. Sassi-Dambron DE, Eakin EG, Ries AL, Kaplan RM. Treatment of dyspnea in COPD: a controlled clinical trial of dyspnea management strategies. Chest 1995; 107: 724-9.

21. Gallefoss F, Bakke PS, Rsgaard PK. Quality of life assessment after patient education in a randomized controlled study on asthma and chronic obstructive pulmonary disease. Am J Respir Crit Care Med 1999; 159: 812-7.

22. Wilkinson T, Donaldson G, Hurst J, Seemungal T, Wedzicha J. Early therapy improves outcomes of exacerbations of chronic obstructive pulmonary disease. Am J Respir Crit Care Med 2004; 169: 1298-1303.

23. Devine EC, Pearcy J. Meta-analysis of the effects of psychoeducational care in adults with chronic obstructive pulmonary disease. Patient Educ Couns 1996; 29: 167-78.

24. Donaldson GC, Seemungal TA, Bhowmik A, Wedzicha JA. Relationship between exacerbation frequency and lung function decline in chronic obstructive pulmonary disease. Thorax 2002; 57: 847-852.

25. Spruit MA, Gosselink R, Troosters T, et al. Muscle force during an acute exacerbation in hospitalized patients with COPD and its relationship with CXCL8 and IGF-I. Thorax 2003; 59: 741-742.

26. Andersson F, Borg S, Jansson SA, et al. The costs of exacerbations in chronic obstructive pulmonary disease. Respir Med 2002; 96: 700-708.

27. Connors AF, Dawson NV, Thomas C, et al. Outcomes following acute exacerbation of severe chronic obstructive lung disease. Am J Respir Crit Care Med 1996; 154: 959-967.

28. World Health Organization. Adherence to long-term therapies: evidence for action. Annex 2003; 1: 143.

29. Bourbeau J, Collet JP, Schwartzman K, Ducruet T, Nault D, Bradley C. Economic benefits of self-management education in COPD. Chest 2006; 130: 1704-11. 


\section{Appendix}

\section{"VILLA PINETA" HOSPITAL - PULMONARY REHABILITATION UNIT}

\section{LEARNING QUESTIONNARIE}

SURNAME

NAME

AGE.......SEX.

COMPILATION DATE..............

Area 1: SYMPTOMS-THERAPY

Health educators involved: PHYSICIAN, RESPIRATORY THERAPIST

Q: $\quad$ What is dyspnoea?

A: $\quad \begin{aligned} & \text { a sensation of difficult breath (correct) } \\ & \text { a sensation of physical weakness }\end{aligned}$

a symptoms regarding digestive system

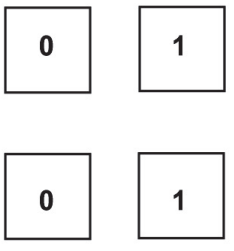

Q: $\quad$ In COPD disease purulent mucus is indicative of

A: $\quad$ suspects bacterial infection of the airways (correct)

a normality condition

it's must be treated with bronchodilators drugs

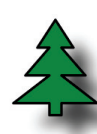

Q: $\quad$ When muscle training should be performed?

A: $\quad$ only during hospital stay

at least for 1 month post discharge

daily, it's must become a part of life-style (correct)

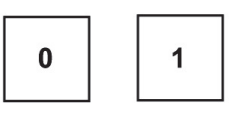

Q: $\quad$ When mucus drainage should be made?

A: always

only in presence of mucus hypersecretion (correct)

only together respiratory therapist

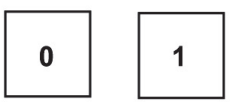

Area 2: AIDS

Health educators involved: NURSE, RESPIRATORY THERAPIST

Q: $\quad$ How much aerosol-therapy should last?

A: $\quad$ more than 30 minute

more than 15 minute

until a maximum of 10 minute (correct)

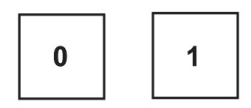

Q: What is the correct position to perform aerosol-therapy?

A: $\quad$ seated (correct)

tended up

lying down

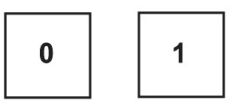

Q: $\quad$ When the prescribed oxygen-therapy is useful?

A: $\begin{aligned} & \text { only when there is dyspnoea } \\ & \text { only at rest }\end{aligned}$

always (correct)

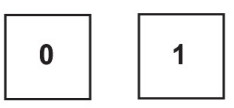

Q: $\quad$ Can the use of oxygen improve attention and memory?
A: $\quad$ yes (correct)
no
maybe

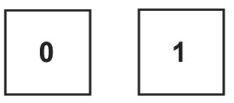

Area 3: MOOD

Health educators involved: PSYCHOLOGIST

Q: $\quad$ Anxiety is

A: $\quad$ an emotive reaction (correct)

a depression sensation linked to physical fatigue

a pulmonary problem

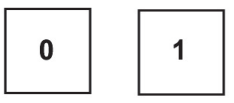

Q: $\quad$ Depression is

A: lack of energy, loss of interest for the activities (correct) daily inability to try happiness

euphoria, increase in energy, good consideration of himself

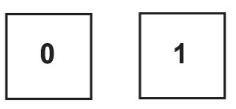

$0=$ Uncorrect answer $\quad 1=$ Correct answer 